
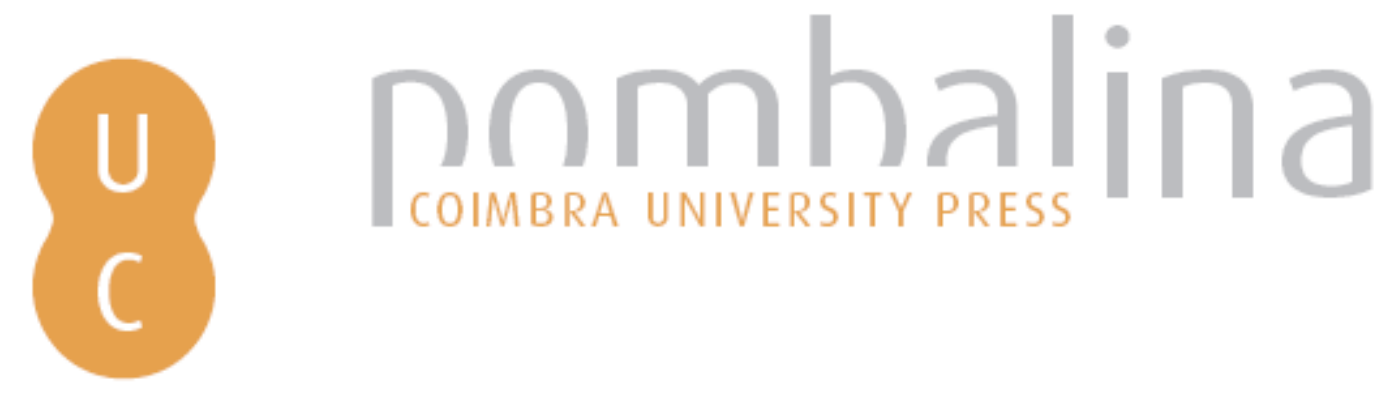

\title{
Estimating net heat flux from surrogate firebrand accumulations using an inverse heat transfer approach
}

Autor(es): $\quad$ Thomas, J. Christian; Mueller, Eric V.; Hadden, Rory M.

Publicado por: Imprensa da Universidade de Coimbra

URL

persistente: URI:http://hdl.handle.net/10316.2/44601

DOI: $\quad$ DOI:https://doi.org/10.14195/978-989-26-16-506_84

Accessed : $\quad$ 26-Apr-2023 15:31:16

A navegação consulta e descarregamento dos títulos inseridos nas Bibliotecas Digitais UC Digitalis, UC Pombalina e UC Impactum, pressupõem a aceitação plena e sem reservas dos Termos e Condições de Uso destas Bibliotecas Digitais, disponíveis em https://digitalis.uc.pt/pt-pt/termos.

Conforme exposto nos referidos Termos e Condições de Uso, o descarregamento de títulos de acesso restrito requer uma licença válida de autorização devendo o utilizador aceder ao(s) documento(s) a partir de um endereço de IP da instituição detentora da supramencionada licença.

Ao utilizador é apenas permitido o descarregamento para uso pessoal, pelo que o emprego do(s) título(s) descarregado(s) para outro fim, designadamente comercial, carece de autorização do respetivo autor ou editor da obra.

Na medida em que todas as obras da UC Digitalis se encontram protegidas pelo Código do Direito de Autor e Direitos Conexos e demais legislação aplicável, toda a cópia, parcial ou total, deste documento, nos casos em que é legalmente admitida, deverá conter ou fazer-se acompanhar por este aviso.

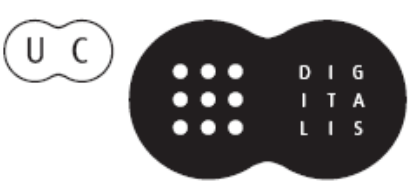




\section{ADVANCES IN}

\section{FOREST FIRE RESEARCH}

\section{8}

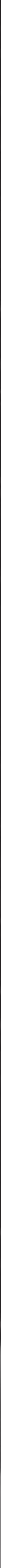




\title{
Estimating net heat flux from surrogate firebrand accumulations using an inverse heat transfer approach
}

\author{
J. Christian Thomas; Eric V. Mueller; Rory M. Hadden* \\ School of Engineering, University of Edinburgh, EH9 3BF, Edinburgh, UK. \\ \{r.hadden@ed.ac.uk*\}
}

\begin{abstract}
An experimental study is presented that investigates the heat flux from firebrand accumulations to a substrate. Surrogate firebrands produced from wood pellets were deposited on an inert solid substrate. An inverse heat transfer model is used with temperature measurements in the substrate to calculate the net heat flux into the substrate. The thermal boundary condition (heat flux) can then be used to assess the hazard from firebrand accumulations and better understand the ignition potential of combustible structural material by firebrands. Peak net heat fluxes were found to be between 4 and $9 \mathrm{~kW} \mathrm{~m}^{-2}$ and to depend primarily on the initial particle temperature. The exposure duration increases with increasing firebrand accumulation mass and decreasing deposition area. For sustained smouldering accumulations, the substrate is exposed to prolonged heating with a net heat flux between 1 and $3 \mathrm{~kW} \mathrm{~m}^{-2}$. Peak gauge heat fluxes were found between 30 and $80 \mathrm{~kW} \mathrm{~m}^{-2}$. This depends on the initial particle temperature and deposition area. The method shown herein is a robust tool to assess hazardous conditions in the wildland-urban interface, related to firebrand accumulations.
\end{abstract}

Keywords: wildfires, embers, experimentation, WUI, wood pellets

\section{Introduction}

The production, transport and deposition of firebrands represent key fire spread mechanisms in wildfires and at the wildland urban interface. This is due to the potential of firebrands to promote fire front propagation, causing long range spotting, and cause ignition of combustible structural material.

Studies available in the literature identify firebrands as a significant cause of structural ignitions in the WUI (Caton 2017). Single firebrands can ignite vegetative litter (e.g. Fernandez-Pello 2015) or porous insulation if they penetrate exterior shell of the structure (Hamann 2017). It is unlikely that a single firebrand will cause ignition of non-porous combustible solids due to the thermal mass of the substrate compared to the heating from the firebrand. However, when firebrands accumulate on solid combustible substrates, the energy transfer from an accumulation of particles may develop a hazardous thermal boundary condition sufficient to promote pyrolysis, charring and ignition (smouldering and/or flaming). A thermal boundary condition in form of a heat flux incident at the surface of combustible material is commonly used in fire safety engineering in the built environment to assess the ignition potential of that material (Torero 2016). It is the intent of this work to generate a methodology that adapts prior knowledge from the built environment to meet wildfire research needs.

A complete solution to the firebrand problem has yet to be established. Significant work has been conducted exploring firebrand production (Thomas 2017, El Houssami 2016, Manzello 2009(a)), transport and spotting (Koo 2010), ignition of porous fuel beds (Ellis 2015, Fernandez-Pello 2015, Viegas 2014, Manzello 2006), and ignition of solids (Hakes 2017(b), Santamaria 2015, Manzello 2014, Manzello 2009(b)). Hakes et al. (2017(a)) and Caton et al. (2017) produced comprehensive summaries of the state of research, which the reader is encouraged to visit.

The experimental study presented shows a methodology to assess the thermal boundary condition using direct heat flux measurements and an inverse heat transfer method. Firebrands are deposited on 
an inert substrate, which is equipped with thermocouples or heat flux gauge. The work focuses on the ignition of solid substrates, investigating the net and incident heat fluxes that are generated from firebrand accumulations. The goal is to assess what magnitude a typical flux is and if this flux causes hazardous conditions for solid combustible substrates.

\section{Methodologies}

\subsection{Fuel}

Commercially available wood pellets were used as surrogate firebrand material (Figure ). The pellets are comprised of Scottish softwood (Puffin Pellets, UK). The pellets have a quoted calorific value of $16.56 \mathrm{~kJ} \mathrm{~g}^{-1}\left(4.6 \mathrm{kWh} \mathrm{kg}^{-1}\right)$, and less than $0.5 \%$ ash content. The diameter was measured to be $6.0 \mathrm{~mm}$ and the mean length of virgin particles was $15.91 \pm 5.30 \mathrm{~mm}$ and projected area was 95.49 $\pm 31.80 \mathrm{~mm}^{2}(\mathrm{~N} \approx 600$, assuming cylindrical pellets). These particles (and resulting firebrands) are, on average, larger than firebrand sizes that has been quoted in literature (Manzello 2009(a), Thomas 2017). The moisture content of virgin wood pellets was $7.15 \pm 0.15 \%$ (dry weight).

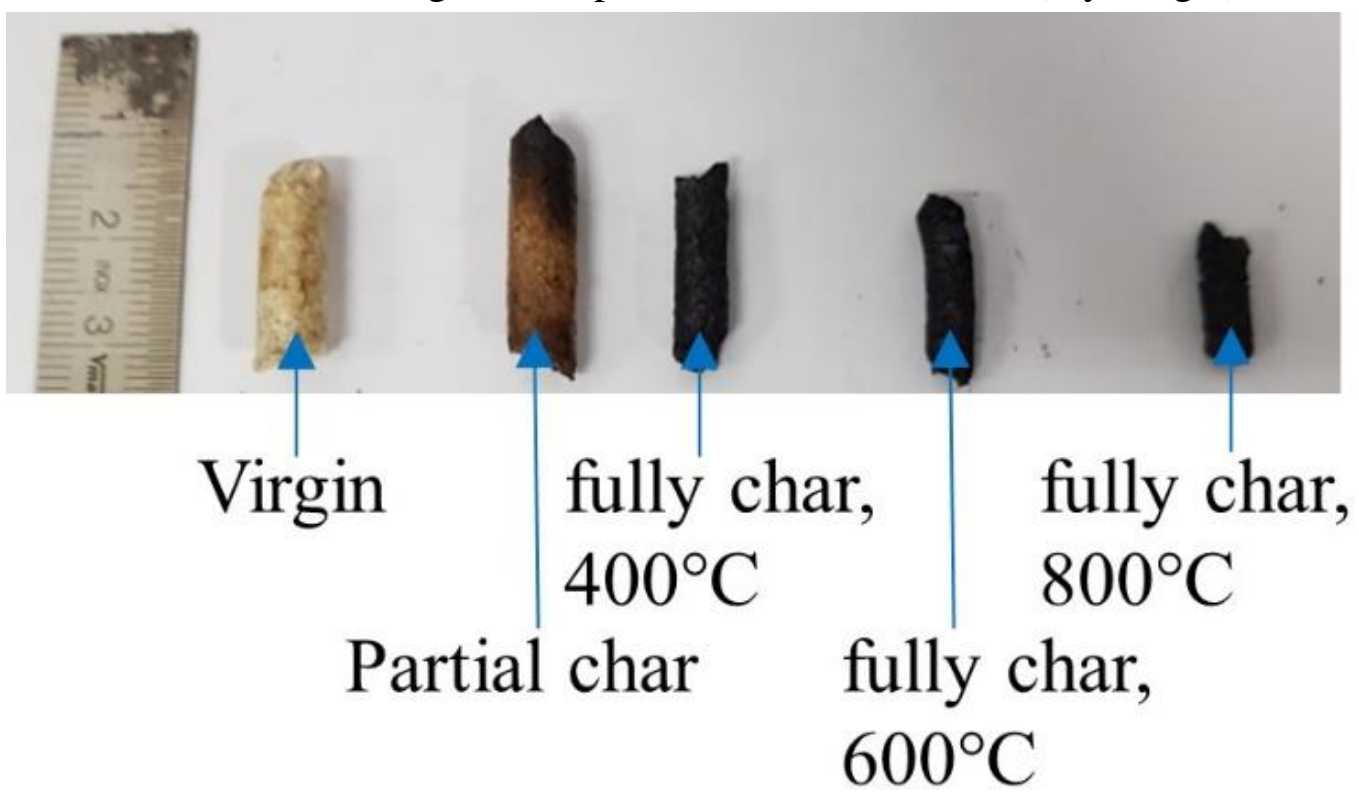

Figure 1 - Pellets used as fuel for firebrand production. At various states of generation. Temperature refers to furnace temperature (condition period: $10 \mathrm{~min}$ )

\subsection{Firebrand production}

Firebrands were produced in a muffle furnace (Nabertherm LE-14/11, Nabertherm GmbH, Germany). The furnace was set to a constant temperature and a known mass of virgin pellets was placed in the furnace for a predetermined period of time. Both the initial mass of firebrands and furnace temperature were varied in this study and the conditioning time was kept constant at $10 \mathrm{~min}$. The initial accumulation masses investigated were 50,100, and $200 \mathrm{~g}$ (of virgin pellets). Oven temperatures were varied between 400,600 and $800{ }^{\circ} \mathrm{C}$. For each initial pellet mass tested, the firebrand accumulation mass produced after conditioning was measured.

The condition of the firebrands was characterised by measuring the mass loss during conditioning at specific intervals. The resulting mass loss curves are shown in Figure . 

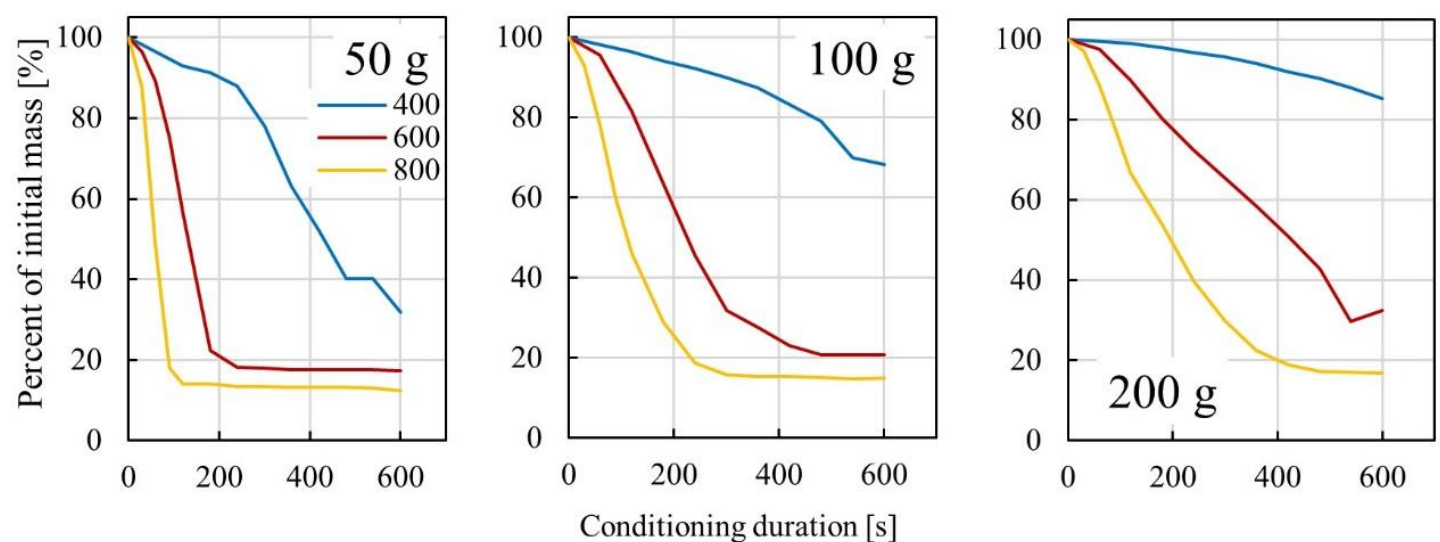

Figure 2 - Mass loss curves of firebrands generated in a muffle furnace with three different initial masses. The values in the legend refer to the furnace temperature in degree Celsius.

During the conditioning period, the virgin material undergoes dehydration, degradation and pyrolysis, and charring processes. The data shown in Figure at $600 \mathrm{~s}$ represent the firebrand mass used in experimentation discussed below. After $600 \mathrm{~s}$ at $800^{\circ} \mathrm{C}$, all samples reach fully charred state. After $600 \mathrm{~s}$ at $600{ }^{\circ} \mathrm{C}$ the $200 \mathrm{~g}$ sample still contains $32 \%$ of the initial mass. At $400{ }^{\circ} \mathrm{C}$ furnace temperature, the firebrand accumulation mass used in experimentation ranges from 32 to $85 \%$ of the initial mass, for 50 and $200 \mathrm{~g}$, respectively.

It is important to know the state of the firebrands when deposited on the substrate, i.e. whether they are partially or fully charred. During conditioning, particle properties (thermal conductivity, particle density, energy content, size, and others) change. These particle properties are important as they will affect the heat transfer between the accumulation and the substrate. The heat of combustion of the particles is also important as this characterises the total energy available in the accumulation. Figure shows pellets after various conditioning periods. For the specific pellets used here, the heat of combustion was determined using Bomb Calorimeter (IKA C1, IKA England LTD, UK) according to the principles of ISO 1716. The heat of combustion are shown in Table .

Table 1 - Heat of combustion results from Bomb Calorimeter experiments (Three repetition per condition).

\begin{tabular}{llll}
\hline & & \multicolumn{2}{c}{ Heat of comb. $\left[\mathrm{kJ} \mathrm{g}^{-1}\right]$} \\
\cline { 3 - 4 } Initial mass $[\mathrm{g}]$ & Furnace temp. $\left[{ }^{\circ} \mathrm{C}\right]$ & Avg. & St.dev. \\
\hline- & - & 18.78 & 0.06 \\
- & - & 19.92 & 0.03 \\
200 & 400 & 21.86 & 2.14 \\
100 & 400 & 22.61 & 2.34 \\
50 & 400 & 28.81 & 0.04 \\
100 & 600 & 33.54 & 0.03 \\
50 & 800 & 32.39 & 0.06 \\
\hline
\end{tabular}

Virgin pellets have the lowest heat of combustion while the fully charred particles have the highest heat of combustion. Sample accumulations with 100 and $200 \mathrm{~g}$ initial mass produced at $400{ }^{\circ} \mathrm{C}$ were a mix of virgin, partially charred and fully charred particles (see Figure ). The average heat of combustion increases, with a higher variability (see standard deviation). These values are comparable to literature values for wood and wood char (Dietenberger 2002). The temperature at which the fully charred particle are produced also has an impact on the heat of combustion although the trend is not entirely evident yet. 


\subsection{Experimental setup}

The experimental setup is shown in Figure below. After conditioning, firebrands were weighed and transported to a containment basket. This basket was made from stainless steel mesh with $63 \%$ perforation. Three different basket sizes are used with $50 \mathrm{~mm}, 75 \mathrm{~mm}$, and $100 \mathrm{~mm}$ diameter. A confined accumulation was used in order to better quantify the accumulation shape, as well as controlling the deposition area.

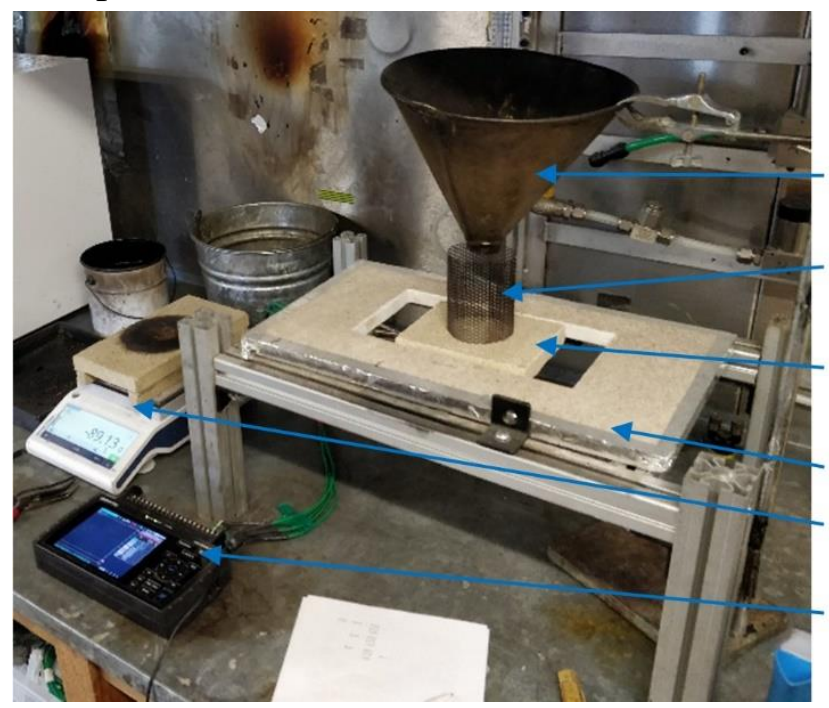

Funnel for deposition

Perforated containment basket

Substrate (vermiculite with

Embedded TCs or HFG)

Work top and frame

Load cell

Data logger

Figure 3 - Experimental setup for generation of firebrands and measuring net heat flux from firebrand accumulations.

Side view of substrate with thermocouple location:

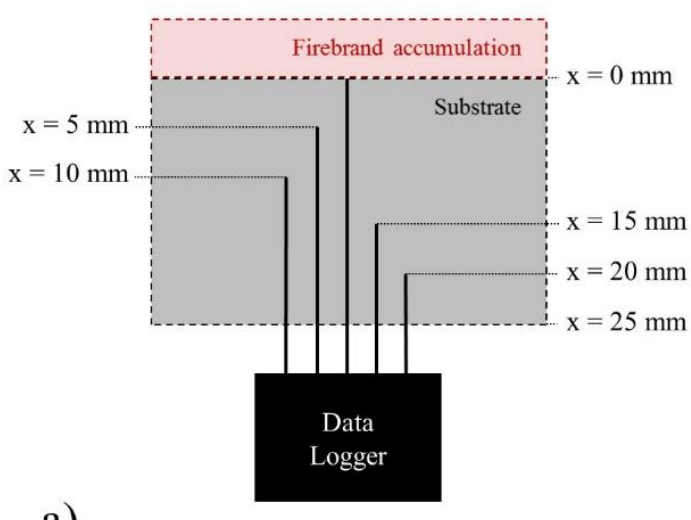

a)

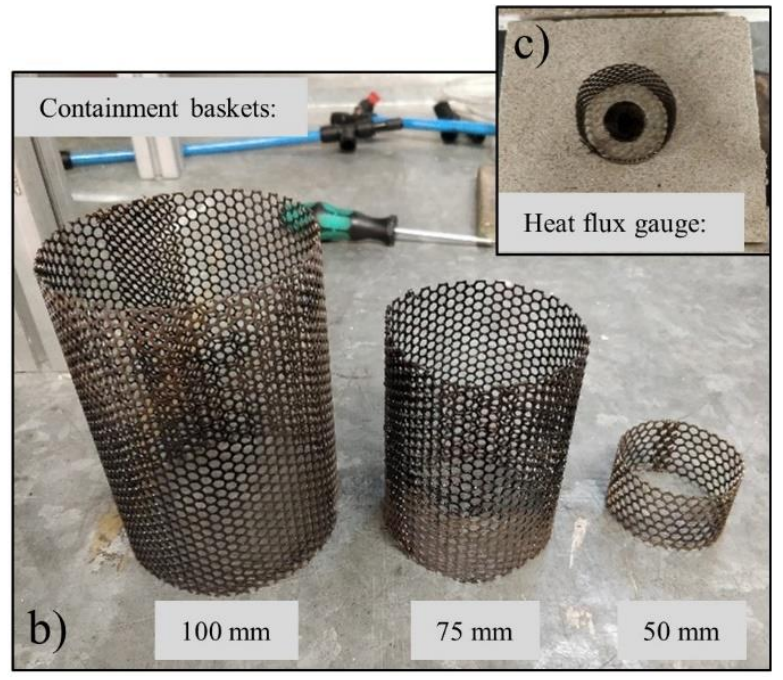

Figure 4 - (a) Schematic of thermocouple layout and (b) containment baskets and (c) heat flux gauge in substrate (with $50 \mathrm{~mm}$ basket).

The substrate used was $25 \mathrm{~mm}$ thick vermiculite insulation board (V-1100(700), Skamol, Denmark). This was chosen because it has similar properties to wood $\left(\rho=700 \mathrm{~kg} \mathrm{~m}^{-3}, k=0.19 \mathrm{~W} \mathrm{~m}^{-}\right.$ ${ }^{1} \mathrm{~K}^{-1}, C_{p}=995 \mathrm{~J} \mathrm{~kg}^{-1} \mathrm{~K}^{-1}$ ). The substrate was either instrumented with five thermocouples (K-type, 1 $\mathrm{mm}$ diameter sheath, grounded) or a water cooled heat flux gauge (Schmidt-Boelter type, Hukseflux Thermal Sensors B.V., UK, SBG01-100). Four thermocouples were located nominally 5, 10, 15, and $20 \mathrm{~mm}$ from the surface of the substrate. One thermocouple was positioned flush with the substrate surface. The heat flux gauge was flush with the surface. Temperature and heat flux data were acquired at $2 \mathrm{~Hz}$. 
In this manuscript the following notation for the description of experiments will be used: "initial accumulation mass-furnace temperature-deposition area diameter". An example is: 050-400-050. This refers to the experiment with $50 \mathrm{~g}$ initial mass, conditioned at $400{ }^{\circ} \mathrm{C}$ with $50 \mathrm{~mm}$ deposition area diameter. Note that the $50 \mathrm{~mm}$ diameter deposition area was only used with $50 \mathrm{~g}$ initial accumulation mass. Experiments with the heat flux gauge were only conducted for a small set of conditions (050400-050/075/100 and 050-800-050).

\subsection{Inverse heat transfer model}

The substrate temperature data was used as input to an inverse heat transfer model. Data from the surface thermocouple were not used in this model. This model outputs the time series of net heat flux into the substrate. Net heat flux into the vermiculite substrate was estimated using an inverse heat transfer calculation method. The 1-D conduction equation was solved numerically for the vermiculite using an implicit Crank-Nicolson scheme (Minkowycz 2006). Density, specific heat capacity and temperature dependent thermal conductivity were determined from manufacturer. Temperature dependent emissivity was obtained from Laschuetza (2017). Convective and radiative heat losses at the back of the substrate were included. The net flux condition at the upper surface was determined using Beck's method for minimizing the sum of squares between measured and estimated in-depth temperatures, using a number of future measurements for a given time step (Beck 1985). In this case, 30 future measurements were for each prediction. The calculated net heat flux is compared to the total heat flux (no losses due to radiation and convection) measured with the heat flux gauge.

\section{Results and discussion}

This section is separated into two parts. First, temperature measurements in the vermiculite substrate will be presented followed by the heat flux measurements.

\subsection{In-depth temperature measurements}

It was observed that in-depth temperature evolutions follow the same trends as the surface temperature for the duration of the experiment (Figure ).

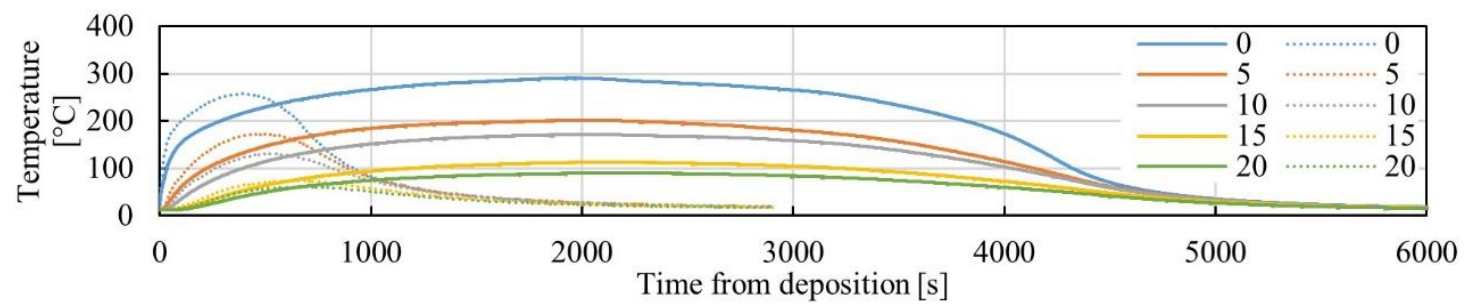

Figure 5 - Typical example of in-depth temperature evolution. Solid: 050-400-050, dotted: 050-800-050. The values in the legend refer to the thermocouple location from the surface, $0 \mathrm{~mm}$ is the surface.

The trend is characterised by a period of rapidly increasing temperature following deposition of the firebrands and a decrease in the temperature as the accumulation cools or is consumed by a smouldering reaction. The duration of the heating period is a function of the accumulation mass, temperature and deposition area.

This is expected, since the substrate is inert and no thermal degradation or combustion processes occur within the substrate matrix. Thus, for simplicity and clarity, most data presented only contain surface temperature measurements for comparison between experimental conditions. A clear distinction can be made between the two experimental conditions depicted in Figure. This distinction can also be made by just observing the temperature at the surface $(x=0 \mathrm{~mm})$.

Before going into detailed analysis, a special case will be discussed: 200-400/800-075/100. Temperature at the substrate surface are shown in Figure . 


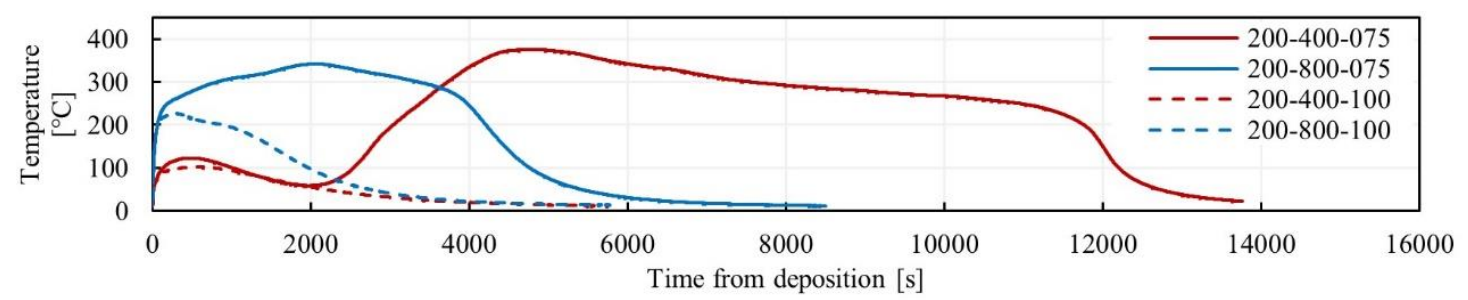

Figure 6 - Temperature evolutions at the surface for selected experiments with $200 \mathrm{~g}$ initial pellet mass.

This condition offers a good example to show importance of firebrand production, accumulation mass and deposition area. When firebrands are produced in a batch of $200 \mathrm{~g}$ at $400{ }^{\circ} \mathrm{C}$, only a small fraction of the initial mass is lost (see Figure ). Most particles are visibly indistinguishable from virgin particles, with some particles charred. When they are deposited on the substrate, they either cool down (200-400-100) or they cool down before a smouldering reaction is initiated which burns for a long duration until almost only ash is left (200-400-075). In the former case, the heat losses from the system are such that the smouldering reaction cannot be sustained. In the second case where the deposition area is smaller, the combination of heat feedback and heat losses are sufficient to drive a sustained smouldering.

When firebrands are created from $200 \mathrm{~g}$ at 600 or $800{ }^{\circ} \mathrm{C}$, the accumulation creates a condition which promotes sustained smouldering (e.g. blue curves in Figure; note that the firebrand mass is now lower compared to red lines). Although the behaviour of accumulations in 200-400-075/100 are interesting, they are outliers to the current data sets and represent conditions where the response of the substrate is dominated by the ignition and propagation of the smouldering fire. Therefore these two conditions will be excluded from the following discussion.

Observations of the peak surface temperatures are presented in Figure . The accumulation masses used in Figure are according to the mass loss curves shown in Figure (at 600s). The peak surface temperatures are grouped by exposure area diameters. Generally, peak surface temperature increase with increasing accumulation mass. For a given accumulation mass the peak temperature increases with decreasing deposition area. Both of these observations can be attributed to the increase in heat feedback and decrease in heat losses. A larger deposition area results in an increase in heat losses to the surrounding from the accumulation (radiative and convective). It is evident, that the range of peak temperatures measured are sufficiently high to cause pyrolysis of cellulosic material and potentially also smouldering in a combustible substrate.

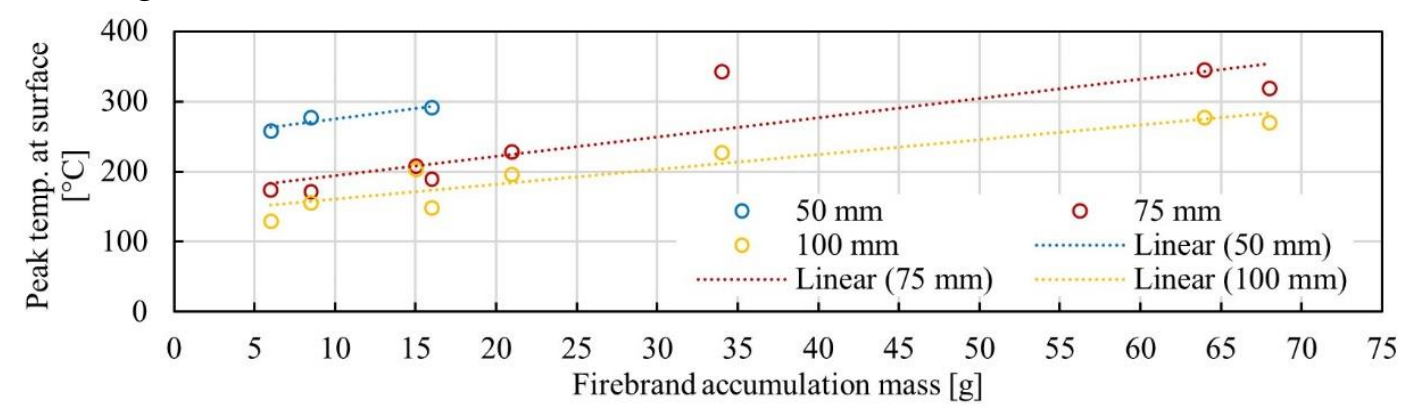

Figure 7 - Peak temperature at substrate surface plotted against firebrand accumulation mass (as deposited). The values in the legend refer to the deposition area diameter. The dotted lines are regression lines as indicated.

Increasing the furnace temperature (and keeping conditioning time constant), decreases the firebrand accumulation mass. Additionally, the initial particle temperature when deposited also increases. Observing experiments when the furnace temperature is raised shows that the peak temperature at the substrate surface only decreases slightly (Figure), the time until the substrate reaches peak temperatures is shorter (Figure ), and the initial temperature rise is faster (Figure and 
Figure ). Results in Figure show that the effect of furnace temperature is stronger for smaller deposition areas.

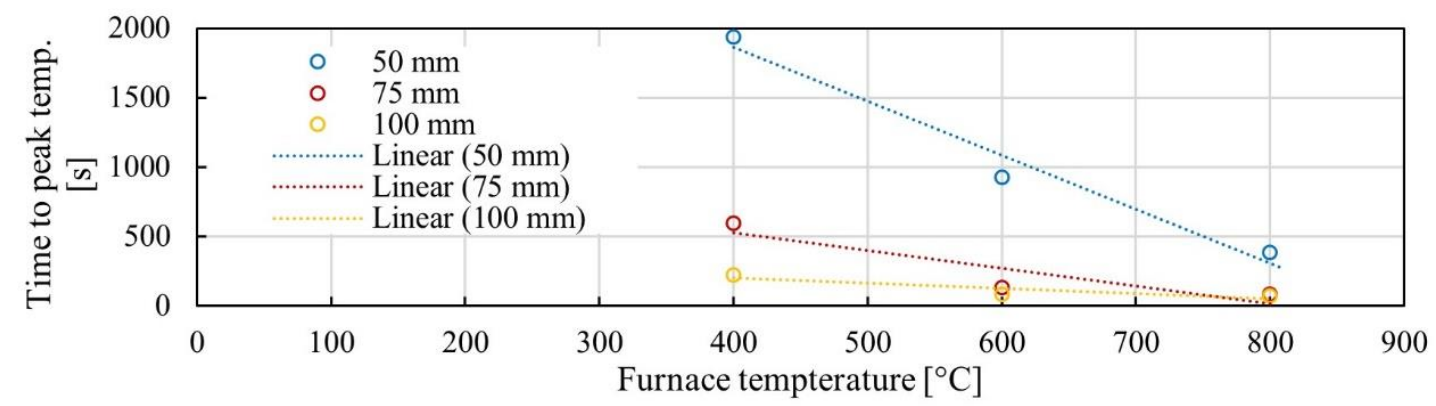

Figure 8 - Time to reach peak surface temperature plotted against furnace temperature for experiments with $50 \mathrm{~g}$ initial pellet mass.

Peak exposure conditions are not the only parameter that is important in this scenario. The duration of exposure is also a critical consideration. A low magnitude exposure applied for a long period may still present a hazardous condition. The exposure duration will be discussed further in the following section, in terms of the net heat flux absorbed by the substrate.

\subsection{Net heat flux}

The results of net heat flux for constant accumulation mass with different deposition areas and furnace temperature are shown in Figure . Deposition occurs at $t=0 \mathrm{~s}$. A positive heat flux represents the energy transferred from the accumulation into the substrate (i.e. heating) and a negative one is energy transfer from the substrate into the accumulation and surrounding (i.e. cooling). Decreasing the deposition area (Figure (a)) results in a deeper accumulation layer favouring prolonged sustained smouldering combustion (where the accumulation conditions are appropriate). The peak net heat flux occurs shortly after deposition followed by a steep drop. No significant difference between the peak net heat fluxes for different deposition areas were observed when the conditioning temperature was constant (Figure (a)) as expected from analysis of the heat transfer problem. For accumulation conditions that support sustained smouldering, for example 050-400-050, the net heat flux slowly decays from approximately $3 \mathrm{~kW} \mathrm{~m}^{-2}$ after 200 seconds to $1 \mathrm{~kW} \mathrm{~m}^{-2}$ after $3000 \mathrm{~s}$.
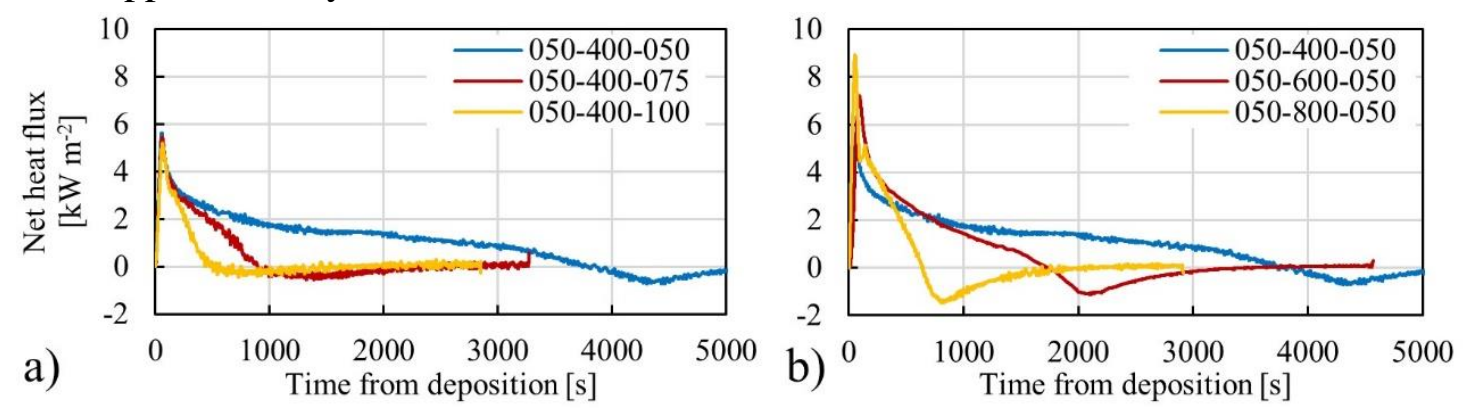

Figure 9 - Net heat flux evolution during experiments with $50 \mathrm{~g}$ initial pellet mass. (a) Varying deposition area. (b) Varying furnace temperature (firebrand accumulation mass).

Particle characteristics are critical to determining the combustion behaviour of accumulations, and firebrands from real fuel source will have properties that differ from these idealized pellets. Density, specific heat, thermal conductivity will likely different as will the particle size and shape. These determine the thermal behaviour, heat losses from the system, and hence the burning behaviour. Chemical composition and energy content are other important characteristics that are likely different. Variation in heat of combustion was already shown for different pellet firebrands (Table ). It was observed in the experimentation that, accumulations with fully charred particles do not sustain smouldering well (e.g. 050-800-050). Contrarily, accumulations with less charred or a mix of fully 
charred and near virgin pellets sustain smouldering significantly better (e.g. 050-400-050). For example, the firebrand mass of "050-400-050" is approximately two and a half times the mass of "050800-050", yet the time of heating (net heat flux $>0 \mathrm{~kW} \mathrm{~m}^{-2}$ ) is almost six times as long. This behaviour is driven in part by bulk properties but also particle properties. Both govern the heat feedback within the accumulation. This also indicates that heat of combustion alone is not sufficient to determine the risk posed by firebrands and that the physical characteristics of the particles and accumulations are also important.

A higher firebrand conditioning temperature results in a higher peak net heat flux. This can be observed in Figure (b). This tendency was observed for all accumulation masses and deposition areas tested and can be attributed to the initial particle temperature and hence a larger driving force for heat transfer. All peak heat fluxes are summarized and plotted in Figure (a) against the furnace temperature.
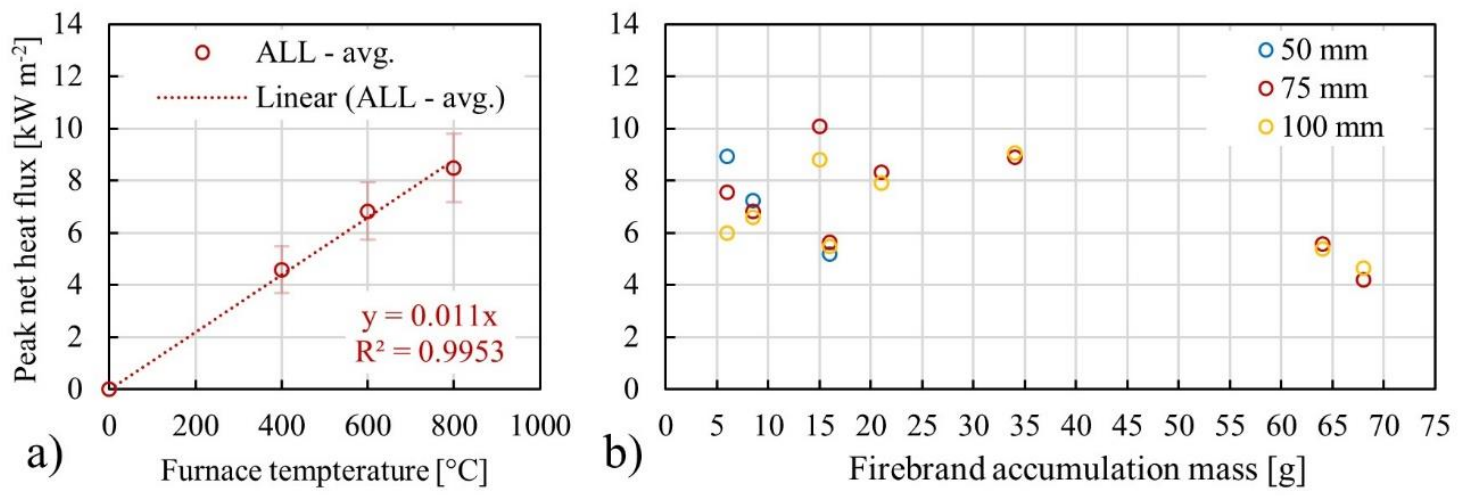

Figure 10 - (a) Averaged Peak net heat flux vs furnace temperature. Error bars: one standard deviation. (b) Peak net heat flux plotted against accumulation mass.

A linear correlation can be observed between the peak net heat flux and the range of furnace temperatures used. The error bars in Figure represent one standard deviation of the averaged values. This indicates that for the peak net heat flux, initial particle temperature is more important than accumulation mass and deposition area. No significant correlation was found between the peak net heat flux and accumulation mass (Figure (b)) again confirming that the condition (temperature/reacting or not reacting) of the particle is a key aspect of defining the risk posed by firebrand accumulations.

As discussed previously, the duration of exposure is an important consideration when defining the ignition risk posed by firebrands. To quantify the duration of exposure, Figure below shows the period of heating with a minimum net heat flux of $1 \mathrm{~kW} \mathrm{~m}^{-2}$.

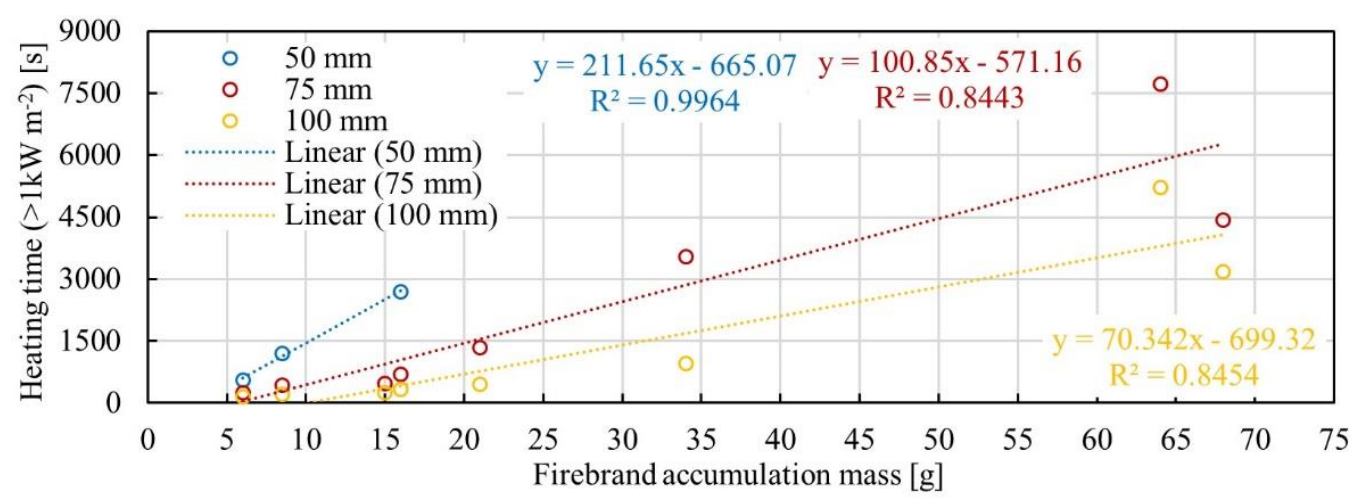

Figure 11 - Duration for which the substrate is heat with at least a net heat flux $>1 \mathrm{~kW}$ m-2 plotted against firebrand mass (as deposited). The values in the legend refer to the deposition area diameter. The dotted lines are regression lines as indicated.

The duration of heating with at least $1 \mathrm{~kW} \mathrm{~m}^{-2}$ (net) increases with increasing accumulation mass and decreasing deposition area. A higher loading on the same deposition area means there is more 
energy available in the accumulation to be transferred into the substrate, thus increasing the duration of heating. Heat feedback increases with decreases deposition area. At the same time, heat losses decrease with decreasing deposition area.

The method for calculating the net heat flux is a 1-dimensional solution. This does not account for radial conductive heat losses in the substrate. The long exposure duration means that in many cases a significant portion of the substrate is heated by conduction through the substrate. As a result, the net heat fluxes presented above are underestimations.

\subsection{Gauge heat flux}

The gauge heat flux describes the total incident heat flux for a given firebrand accumulation. This is contrasted with the net heat flux which is dependent on substrate properties and accounts for heat losses. The net heat flux is the portion of the incident heat flux that transferred into the substrate. A comparison of the two measurements is shown in Figure for experiments with $50 \mathrm{~g}$ initial mass and varying deposition area and furnace temperature.

Peak gauge heat fluxes range from 30 to $80 \mathrm{~kW} \mathrm{~m}^{-2}$. These were found to decrease with increasing deposition area, which suggests that the cooling of the particles when the accumulation is less densely packed is significant. The peak gauge heat flux is reached instantly after deposition, whereas, the time to reach peak net heat flux shows a delay. This is due to the short response time of the heat flux gauge compared to the longer response time of the vermiculite due to the diffusion of the thermal wave.
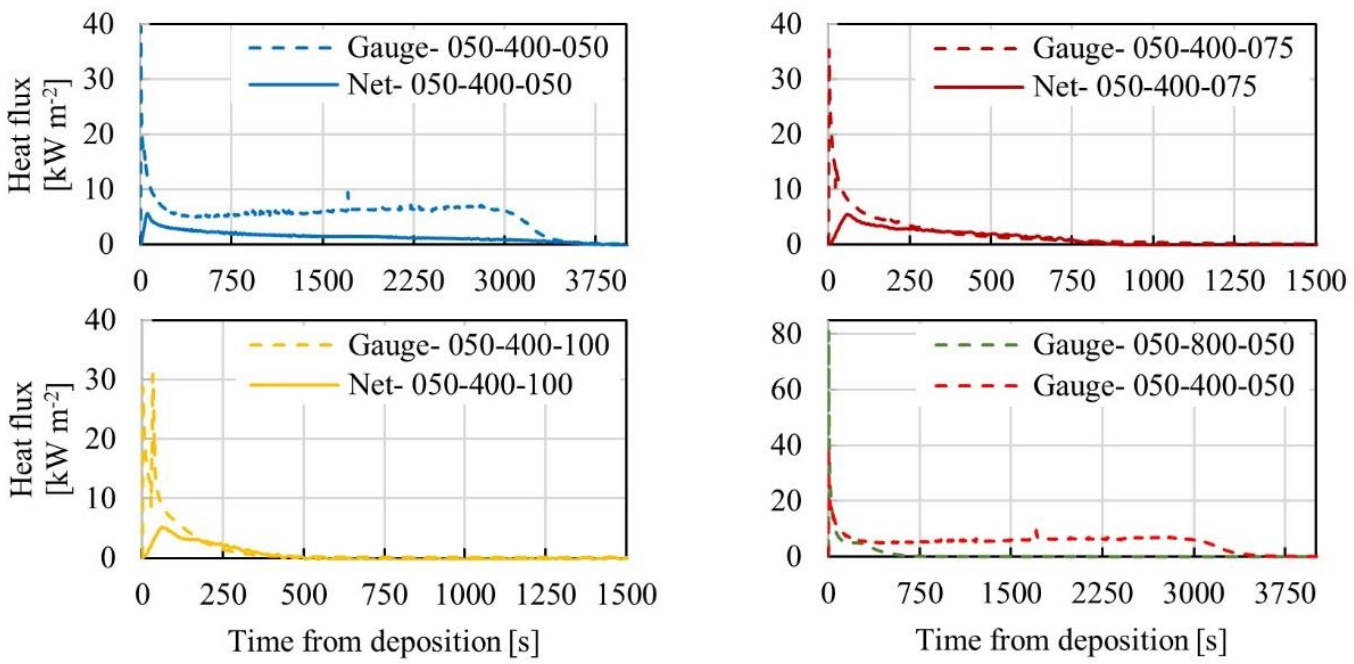

Figure 12 - Comparison between net and gauge heat flux evolution for experiments with $50 \mathrm{~g}$ initial pellet mass, varying deposition area and furnace temperature.

The measured peak gauge heat fluxes are high enough to induce flaming ignition of common materials (Torero 2016), provided they are applied for a sufficient period of time and enough oxidizer is allowed to reach the reaction zone. Peak and one minute average heat flux (net and gauge) are shown in Table. The averaged value is from the first minute after deposition.

Table 2 - Summary of peak and 1-min averaged heat fluxes. The average is the first minute after deposition.

\begin{tabular}{lllll}
\hline & \multicolumn{2}{c}{ Gauge heat flux $\left[\mathrm{kW} \mathrm{m}^{-2}\right]$} & \multicolumn{2}{c}{ Net heat flux $\left[\mathrm{kW} \mathrm{m}^{-2}\right]$} \\
\cline { 2 - 5 } Experiment ID & Peak & 1-min avg. & Peak & 1-min avg. \\
\hline $050-400-050$ & 39.6 & 17.4 & 5.63 & 3.11 \\
$050-400-075$ & 35.3 & 13.7 & 5.47 & 2.76 \\
$050-400-100$ & 30.9 & 15.2 & 5.20 & 2.52 \\
$050-800-050$ & 79.8 & 21.5 & 8.93 & 5.06 \\
\hline
\end{tabular}

The 1-min average gauge heat fluxes as well as the peak fluxes are above typical critical heat flux required to cause flaming ignition of common materials $\left(\sim 12-15 \mathrm{~kW} \mathrm{~m}^{-2}\right.$ radiative flux $)$. This illustrates 
that flaming ignition may be possible as a result of sustained heating by a firebrand accumulation. Certainly these heat fluxes are sufficient to cause pyrolysis and charring of common materials. It has been documented (Manzello 2009(b)) that flaming ignition is unlikely without forced airflow in this type of scenario (it was not observed in this study). This indicates, that under natural convection, the oxidizer flow is insufficient to support flaming combustion. and is a critical mechanism for the ignition process in this type of scenario.

Table (and the bottom right graph in Figure ) shows heat flux results for experiments with firebrands produced at higher furnace temperatures (050-800-050). These results show that peak gauge heat fluxes from accumulations produced at $800{ }^{\circ} \mathrm{C}$ are double that of accumulations produced at 400 ${ }^{\circ} \mathrm{C}$. The 1-min averaged gauge heat flux however is only a fraction larger compared to the one from accumulation produced at lower temperatures. After deposition, particles are initially hotter, but also experience much larger heat losses (convection and radiation), and therefore cool more rapidly.

Results discussed herein provide a quantification of the thermal boundary condition that develops when firebrands are deposited on a solid substrate. Although the net heat flux will change when using different substrates, vermiculite is a good benchmark to estimate what flux levels can be expected for wood and wood products due to the similar thermal properties. With more experimentation, it is desired to solidify findings and correlations, and eventually extrapolate the thermal boundary conditions to combustible substrates.

\section{Conclusions}

The heat flux from firebrand accumulations was investigated using direct heat flux measurements and an inverse heat transfer approach:

- Peak heat fluxes are mainly driven by initial particle temperature upon deposition.

- Duration of exposure is driven by firebrand accumulation mass and deposition area.

- Sustained smouldering of accumulations is a factor of deposition area, accumulation mass and particle properties.

- Peak heat fluxes range from 30-80 $\mathrm{kW} \mathrm{m}^{-2}$ (gauge) and 4-9 $\mathrm{kW} \mathrm{m}^{-2}$ (net).

- Sustained smouldering of accumulations produces heat fluxes of 5-7 $\mathrm{kW} \mathrm{m}^{-2}$ (gauge) and 1-3 $\mathrm{kW} \mathrm{m}{ }^{-2}$ (net).

The findings show that high temperature firebrands many not represent most dangerous condition as these particles do not retain high temperatures for long periods of time. A prolonged exposure at lower heat fluxes (arising from lower temperature firebrands) may be sufficient to cause significant pyrolysis, degradation and charring of a substrate. These accumulations are capable of sustaining smouldering compared to fully charred particle accumulations. Thus, these may be considered more hazardous to solid combustible structural material.

\section{Acknowledgements}

The Authors would like to thank the Joint Fire Science Program for their financial support (JFSP \#15-01-04-55). Furthermore, the authors thank Cameron MacLeod for his assistance with the experimental work.

\section{References}

Beck JV, Blackweel B, St Clair CR (1985) Inverse heat conduction, Ill-posed problems. (WileyInterscience Publication, New York, USA) 
Caton SE, Hakes RSP, Gorham DJ, Zhou A, Gollner MJ (2017) Review of Pathways for Building Fire Spread in the Wildland Urban Interface Part I: Exposure Conditions. Fire Technology 53, 429-473.

Dietenberger M (2002) Update for combustion properties of wood components. Fire and Materials 26, 255-267.

El Houssami M, Mueller E, Thomas JC, Simeoni A, Filkov A, Skowronski N, Gallagher MR, Clark K, Kremens R (2016) Experimental Procedures Characterising Firebrand Generation in Wildland Fires. Fire Technology 52, 731-751.

Ellis PFM (2015) The likelihood of ignition of dry-eucalypt forest litter by firebrands. International Journal of Wildland Fire 24, 225-235.

Fernandez-Pello AC, Lautenberger C, Rich D, Zak C, Urban J, Haddden R, Scott S, Fereres S (2015) Spot fire ignition of natural fuel beds by hot metal particles, embers and sparks. Combustion Science and Technology 187, 269-295.

Hakes RSP, Caton SE, Gorham DJ, Zhou A, Gollner MJ (2017a) A Review of Pathways for Building Fire Spread in the Wildland Urban Interface Part II: Response of Components and Systems and Mitigation Strategies in the United States. Fire Technology 53, 475-515.

Hakes RSP (2017b) Thermal characterization of firebrand piles. (University of Maryland, USA, MS Thesis)

Hamann E, Bahrani B, Kadel J, Stickles M, Zhou A (2017) Ignition of attic insulation foams subjected to firebrand. Proceedings of the 15th International Conference on Fire and Materials, 727-739.

Koo E, Pagni PJ, Weise DR, Woycheese JP (2010) Firebrands and spotting ignition in large-scale fires. International Journal of Wildland Fire 19, 818-843.

Laschuetza T (2017) Numerical and experimental investigation of a Thin Skin Calorimeter (TSC). University of Edinburgh, Edinburgh, UK. MSc Thesis.

Manzello SL, Cleary TG, Shields JR, Yang JC (2006) Ignition of mulch and grasses by firebrands in wildland-urban interface fires. International Journal of Wildland Fire 15, 427-431.

Manzello SL. Maranghides A, Shields JR, Mell WE, Hayashi Y, Nii D (2009a) Mass and size distribution of firebrands generated from burning Korean pine (Pinus koraiensis) trees. Fire and Materials 33, 21-31.

Manzello SL, Park SH, Cleary TG (2009b) Investigation on the ability of glowing firebrands deposited within crevices to ignite common building material. Fire Safety Journal 44 894-900.

Manzello SL (2014) Enabling the investigation of structure vulnerabilities to wind-driven firebrand showers in wildland-urban interface (WUI) fires. Fire Safety Science 11, 83-96.

Minkowycz WJ, Sparrow EM, Murthy JY (Eds) (2006) Handbook of Numerical Heat Transfer (John Wiley \& Sons, Inc., New York, USA)

Santamaria S, Kempna K, Thomas JC,El Houssami M, Mueller M, Kasimov D, Filkov D, Gallagher MR, Skowronski N, Hadden R, Simeoni A (2015) Investigation of Structural Wood Ignition by Firebrand Accumulation. Proceedings of the 1st International Conference on Structural Safety under Fire and Blast, Glasgow, UK.

Thomas JC, Mueller EV, Santamaria S, Gallagher M, El houssami M, Filkov A, Clark K, Skowronski N, Hadden RM, Mell W, Simeoni A (2017) Investigation of firebrand generation from and experimental fire: Development of a reliable data collection methodology. Fire Safety Journal 91 864-871.

Torero JL (2016) SFPE Handbook - Flaming Ignition of Solid Fuels. 5th ed. Society of Fire Protection Engineers.

Viegas DX, Alemaida M, Raposo J, Viegas CX (2014) Ignition of Mediterranean fuel beds by several types of firebrands. Fire Technology 50, 61-77. 